\title{
Sporobacterium olearium gen. nov., sp. nov., a new methanethiol-producing bacterium that degrades aromatic compounds, isolated from an olive mill wastewater treatment digester
}

\author{
Tahar Mechichi, ${ }^{1}$ Marc Labat, ${ }^{1}$ Jean-Louis Garcia, ${ }^{1}$ Pierre Thomas ${ }^{2}$ \\ and Bharat K. C. Patel ${ }^{3}$ \\ Author for correspondence: Bharat K. C. Patel. Tel: +61417726 671. Fax: +61738757656 . \\ e-mail: bharat@genomes.sci.gu.edu.au
}

1 Laboratoire ORSTOM de Microbiologie des Anaérobies, Université de Provence, CESB-ESIL case 925, 163 Avenue de Luminy, 13288 Marseille Cedex 9, France

2 Departement de Biologie, Université de la

Méditerranée, 13288

Marseille Cedex 9, France

3 School of Biomolecular and Biomedical Sciences, Faculty of Science, Griffith University, Brisbane, Queensland 4111

Australia

\begin{abstract}
A strictly chemo-organotrophic, anaerobic bacterium was isolated from an olive mill wastewater treatment digester on syringate and designated strain SR1'. The cells were slightly curved rods, stained Gram-positive and possessed terminal spores. Strain SR1' utilized crotonate, methanol and a wide range of aromatic compounds including 3,4,5-trimethoxybenzoate (TMB), 3,4,5trimethoxycinnamate (TMC), syringate, 3,4,5-trimethoxyphenylacetate (TMPA), 3,4,5-trimethoxyphenylpropionate (TMPP), ferulate, sinapate, vanillate, 3,4dimethoxybenzoate, 2,3-dimethoxybenzoate, gallate, 2,4,6-trihydroxybenzoate (THB), pyrogallol, phloroglucinol and quercetin as carbon and energy sources. Acetate and butyrate were produced from aromatic compounds, methanol and crotonate whereas methanethiol (MT) was produced from methoxylated aromatic compounds and methanol. Strain SR1' had a G+C content of $38 \mathrm{~mol} \%$ and grew optimally between 37 and $40{ }^{\circ} \mathrm{C}$ at pH 7.2 on a crotonate-containing medium. Phylogenetically, strain SR1 ${ }^{\top}$ was a member of cluster XIVa of the Clostridiales group and shared a sequence similarity of $90 \%$ with Clostridium aminovalericum and Eubacterium fissicatena. Consequently, its precise neighbourliness to any one of them depended on the selection of strains of the cluster. On the basis of the phylogenetic and phenotypic evidence presented in this paper, the designation of strain SR1' as Sporobacterium olearium gen. nov., sp. nov. is proposed. The type strain is SR1' ( = DSM 12504').
\end{abstract}

Keywords: Sporobacterium olearium, anaerobic degradation, aromatic compounds, methanethiol, ring cleavage

\section{INTRODUCTION}

Anaerobic degradation of aromatic compounds by pure cultures under fermentative conditions is possible with highly oxidized compounds. These include polyhydroxylated aromatic compounds such as resorcinol, phloroglucinol and gallate, which can be degraded by Coprococcus spp. (Patel et al., 1981), Eubacterium

\footnotetext{
Abbreviations: DMS, dimethylsulfide; MT, methanethiol; THB, 2,4,6trihydroxybenzoate; TMB, 3,4,5-trimethoxybenzoate; TMC, 3,4,5-trimethoxycinnamate; TMPA, 3,4,5-trimethoxyphenylacetate; TMPP, 3,4,5-trimethoxyphenylpropionate.

The GenBank accession number for the $16 \mathrm{~S}$ rRNA sequence of strain SR $1^{\top}$ is AF116854.
}

oxidoreducens (Krumholz \& Bryant, 1986), Pelobacter acidigallici (Schink \& Pfennig, 1982) and Pelobacter massiliensis (Schnell et al., 1991). In the case of Eubacterium oxidoreducens, but not Pelobacter or Coprococcus species, formate or hydrogen is necessary for growth and aromatic compound degradation. In other cases, phenolic compounds which do not contain hydroxyl groups in the meta-position, e.g. hydroquinone (1,4-dihydroxybenzene), have been shown to be degraded by the fermentative bacterium Syntrophus gentianae (Szewzyk \& Schink, 1989). In general, monohydroxylated aromatic compounds are not degraded by pure cultures of fermentative bacteria, but recently a new isolate, designated Sporotomaculum hydroxybenzoicum (Brauman et al., 1998), was re- 
ported to use 3-hydroxybenzoate as the sole carbon source, suggesting that the degradation of the substrate was carried out via the benzoyl-CoA pathway subsequent to the removal of the hydroxyl group. Holophaga foetida (Liesack et al., 1994) and Sporobacter termitidis (Grech-Mora et al., 1996) represent yet another group of fermentative, aromatic compounddegrading bacteria which have been reported to transfer an ether-linked methyl group to sulfide, resulting in the formation of methanethiol (MT) and dimethylsulfide (DMS). The demethylated aromatic compound that is produced is further degraded to acetate, via the phloroglucinol pathway. The ability to degrade aromatic compounds appears to be widely distributed in different phylogenetic groups: for example, $H$. foetida, $P$. acidigallici and $P$. massiliensis are members of the Proteobacteria, whereas Sporobacter termitidis and Coprococcus spp. are members of the sub-branch of the low-G+C-content Gram-positive clostridial group. This paper reports the isolation and characterization of a new bacterium that ferments aromatic compounds to acetate and butyrate, with the production of MT from methyl groups and sulfide.

\section{METHODS}

Source of strains. Strain SR $1^{\mathrm{T}}$ was isolated from enrichment cultures that had been initiated with the liquid content of an anaerobic methanogenic digester fed with olive mill wastewater. The digester samples were collected anaerobically using $\mathrm{N}_{2}$-flushed syringes. Strain $\mathrm{SR} 1^{\mathrm{T}}$ was routinely cultured and maintained in the basal medium supplemented with $5 \mathrm{mM}$ syringate, as described below.

Culture media. A basal medium used for enrichment, isolation and routine cultivation was prepared using the anaerobic techniques described by Hungate (1969), as modified for use with syringes (Macy et al., 1972; Miller \& Wollin, 1974). The basal medium contained (per litre of deionized water): $1 \mathrm{~g} \mathrm{NH}_{4} \mathrm{Cl}, 0.3 \mathrm{~g} \mathrm{~K}_{2} \mathrm{HPO}_{4}, 0.3 \mathrm{~g} \mathrm{KH}_{2} \mathrm{PO}_{4}$, $0.6 \mathrm{~g} \mathrm{NaCl}, 0 \cdot 1 \mathrm{~g} \mathrm{CaCl}_{2} .2 \mathrm{H}_{2} \mathrm{O}, 0.2 \mathrm{~g} \mathrm{MgCl}_{2} .6 \mathrm{H}_{2} \mathrm{O}, 0 \cdot 1 \mathrm{~g}$ $\mathrm{KCl}, 0.5 \mathrm{~g}$ cysteine $\mathrm{HCl}, 1 \mathrm{~g}$ yeast extract (Difco), $1.5 \mathrm{ml}$ trace-element solution (Widdel \& Pfennig, 1981) and $1 \mathrm{mg}$ resazurin. The $\mathrm{pH}$ was adjusted to 7.0 with $10 \mathrm{M} \mathrm{KOH}$ solution and the medium boiled under a stream of $\mathrm{O}_{2}$-free $\mathrm{N}_{2}$ gas and cooled to room temperature; $5 \mathrm{ml}$ aliquots were dispensed into Hungate tubes under $\mathrm{N}_{2} / \mathrm{CO}_{2}$ $(80: 20 \%, v / v)$ and subsequently sterilized by autoclaving at $110^{\circ} \mathrm{C}$ for $45 \mathrm{~min}$. Prior to use, $0.2 \mathrm{ml} 5 \%(\mathrm{w} / \mathrm{v}) \mathrm{NaHCO}_{3}$ and $0.05 \mathrm{ml} 2.5 \%(\mathrm{w} / \mathrm{v}) \mathrm{Na}_{2} \mathrm{~S} .9 \mathrm{H}_{2} \mathrm{O}$ were injected from sterile stock solutions into pre-sterilized basal medium.

Enrichment and isolation. A $0.5 \mathrm{ml}$ sample of liquid from the digester was inoculated into $5 \mathrm{ml}$ basal medium containing $5 \mathrm{mM}$ syringate; this was followed by incubation at $37^{\circ} \mathrm{C}$. The enrichment culture was subcultured several times under the same conditions and then serial 10 -fold dilutions were inoculated into roll tubes containing basal medium supplemented with $5 \mathrm{mM}$ syringate and $1.6 \%(\mathrm{w} / \mathrm{v})$ agar. Several single well-isolated colonies that developed were picked and resuspended; the purification procedure was then repeated several times. One of these cultures was designated strain $\mathrm{SR} 1^{\mathrm{T}}$ and characterized further.

Physiological tests. Substrate- and electron-acceptor utilization, $\mathrm{pH}$, temperature and $\mathrm{NaCl}$ growth-range determin- ations were performed as described by Mechichi et al. (1999).

Light microscopy and electron microscopy. Light- and electron microscopy were performed as described previously (Fardeau et al., 1997).

Analytical methods. Growth was measured at $580 \mathrm{~nm}$ by inserting anaerobic Hungate tubes directly into the cuvette holder of a Shimadzu model UV 160A spectrophotometer. Aromatic compounds were measured by HPLC with a model 1100 chromatograph equipped with a UV detector set at $240 \mathrm{~nm}$ and a 100-position autosampler/autoinjector (Hewlett Packard). Separation was achieved using a $C_{18}$ SYMMETRY $(4.6 \times 100 \mathrm{~mm}, 3.5 \mu \mathrm{m}$ particle size $)$ column (Waters Chromatography) maintained at $35^{\circ} \mathrm{C}$. The mobile phase, consisting of a mixture of two solvents (water in $0.01 \%$ acetic acid and methanol) was used at a flow rate of $0.75 \mathrm{ml} \mathrm{min}{ }^{-1}$. For separation of aromatic compounds, a $20 \%$ methanol solvent phase was initially held for 4 min, then the concentration was increased to $40 \%$ over a period of $24 \mathrm{~min}$; this was followed by washing for $6 \mathrm{~min}$, during which the concentration of methanol was increased to $100 \%$. The column was re-equilibrated with $20 \%$ methanol for at least $5 \mathrm{~min}$ before the next injection. Quantification was performed using external standards.

Acetate and butyrate were measured by HPLC (Spectra Series 100 model; Thermo Separation Products) equipped with an Aminex HPX-87X column $300 \times 7.8 \mathrm{~mm}$ (i.d.) (Bio$\mathrm{Rad}$ ) connected to a differential refractometer (RID-6A; Shimadzu). Analysis was performed using a CR-6A Shimadzu integrator. The mobile phase was $0.005 \mathrm{~N} \mathrm{H}_{2} \mathrm{SO}_{4}$ at a flow rate of $0.6 \mathrm{ml} \mathrm{min}^{-1}$, the temperature of the column was $35^{\circ} \mathrm{C}$, and the volume of the injection loop was $20 \mu \mathrm{l}$.

MT was detected on a Chromosorb WAW 80/100-mesh sp100 column (Alltech) using a Girdel gas chromatograph (Girdel) equipped with a flame-ionization detector and a CR6A Chromatopac integrator (Shimadzu). $\mathrm{N}_{2}$ was used as the carrier gas.

Determination of $\mathbf{G}+\mathbf{C}$ content. DNA was isolated and purified and the $\mathrm{G}+\mathrm{C}$ content was determined by using HPLC, as described by Mesbah et al. (1989), at the DSMZ-Deutsche Sammlung von Mikroorganismen und Zellkulturen GmbH, Braunschweig, Germany. Unmethylated $\lambda$ DNA (Sigma) was used as the standard.

DNA extraction and amplification of the 16S rRNA gene. DNA was extracted from the isolate as described previously (Redburn \& Patel, 1993; Andrews \& Patel, 1996). The universal primers Fd1 and Rd1 were used to obtain a PCR product of approximately $1.5 \mathrm{~kb}$ corresponding to base positions 8-1542, on the basis of Escherichia coli numbering of the 16S rDNA (Winker \& Woese, 1991). A $50 \mu$ l reaction contained $1-20$ ng genomic DNA, $1 \mu \mathrm{M}$ in the case of each primer, $5 \mu \mathrm{l} 10 \times$ buffer, $200 \mu \mathrm{M} \mathrm{dNTP,} 3.5 \mathrm{mM} \mathrm{MgCl}{ }_{2}$ and 2.5 U Taq polymerase (Promega). PCR was carried out using an initial denaturation at $94^{\circ} \mathrm{C}$ for $7 \mathrm{~min}$, then 29 cycles of annealing at $55^{\circ} \mathrm{C}$ for $2 \mathrm{~min}$, extension at $72^{\circ} \mathrm{C}$ for $4 \mathrm{~min}$, denaturation at $94^{\circ} \mathrm{C}$ for $1 \mathrm{~min}$ and, finally, an extension cycle comprising $55^{\circ} \mathrm{C}$ for $2 \mathrm{~min}$ and $72{ }^{\circ} \mathrm{C}$ for 20 $\min$.

Direct sequencing of PCR products. PCR products were purified using the QIAquick Kit (Qiagen). The DNA concentration of the purified PCR product was estimated by comparison with the Low Mass Ladder (Gibco-BRL) on an agarose gel containing ethidium bromide. QIAquick-purified PCR products were sequenced using the ABI PRISM Dye Terminator Cycle Sequencing Kit containing AmpliTaq 
FS DNA polymerase and the ABI 373A sequencer. A $10 \mu \mathrm{l}$ reaction contained $35 \mathrm{ng}$ PCR product, $4 \mu$ l cycle sequencing reaction mix, $3.2 \mathrm{pmol}$ primer and $2 \cdot 5 \mu \mathrm{g}$ BSA. Thermal cycling was carried out using a RapidCycler (Idaho Technology) at a temperature transition slope of 2 , an initial denaturation at $94^{\circ} \mathrm{C}$ for $15 \mathrm{~s}$, then 25 cycles of denaturation at $94^{\circ} \mathrm{C}$ for $0 \mathrm{~s}$, annealing at $50^{\circ} \mathrm{C}$ for $10 \mathrm{~s}$ and extension at $60{ }^{\circ} \mathrm{C}$ for $3 \mathrm{~min}$.

Sequence alignments and phylogenetic inferences. The new sequence data generated were aligned and an almost fulllength consensus 16S rRNA gene sequence was assembled and checked for accuracy manually using the alignment editor, ae2 (Maidak et al., 1997). These sequence data were compared with other sequences in the GenBank database (Benson et al., 1993) using BLAST (Altschul et al., 1997) and, in the Ribosomal Database Project, version 7.0, using SIMILARITY_rank and SUGGEST_tree (Maidak et al., 1997). Pairwise evolutionary distances based on 978 unambiguous nucleotides were computed using DNADIST (Jukes \& Cantor, 1969) and neighbour-joining programs that form part of the PHYLIP suite of programs (Felsenstein, 1993). TREECON was used extensively for bootstrap analysis (Van de Peer \& De Wachter, 1993).

\section{RESULTS}

\section{Enrichment and isolation}

An enrichment culture that was positive for growth on syringate after 2 weeks incubation at $37^{\circ} \mathrm{C}$ was serially diluted and subcultured several times. A stable microbial consortium that developed degraded syringate with concomitant production of acetate and butyrate and consisted of a morphologically dominant bacterial population. Subsequently, this enrichment culture was serially diluted and used to inoculate roll tubes. Colonies developed within 4 weeks incubation, after which single, well-isolated colonies were picked; this procedure was repeated several times. A pure culture, designated as strain $\mathrm{SR}^{\mathrm{T}}$, was selected for further characterization.

\section{Cellular morphology}

Cells of strain SR $1^{\mathrm{T}}$ were slightly curved rods $(5-10 \mu \mathrm{m}$ $\times 0 \cdot 4-0 \cdot 8 \mu \mathrm{m}$ ) (Fig. 1a). Some cells possessed terminal spherical spores that caused distension of the sporangium. The cells stained Gram-positive and electron micrographs of thin sections of the cells showed the presence of a thick, bilayered cell wall structure (Fig. lb) resembling Gram-positive-type cell walls. Cells were motile: negatively stained cells showed evidence of peritrichous flagella (Fig. 1c).

\section{Effects of temperature, $\mathrm{pH}$ and $\mathrm{NaCl}$}

The temperature range for growth was $25-45^{\circ} \mathrm{C}$, the optimal temperature for growth being between 37 and $40^{\circ} \mathrm{C}$. The $\mathrm{pH}$ range for growth was between 6.5 and $8 \cdot 5$, with an optimum at $7 \cdot 2$. The $\mathrm{NaCl}$ concentration range for growth was between 0 and $30 \mathrm{~g} \mathrm{l}^{-1}$, the optimal concentration for growth being between 1 and $3 \mathrm{~g} \mathrm{l}^{-1}$
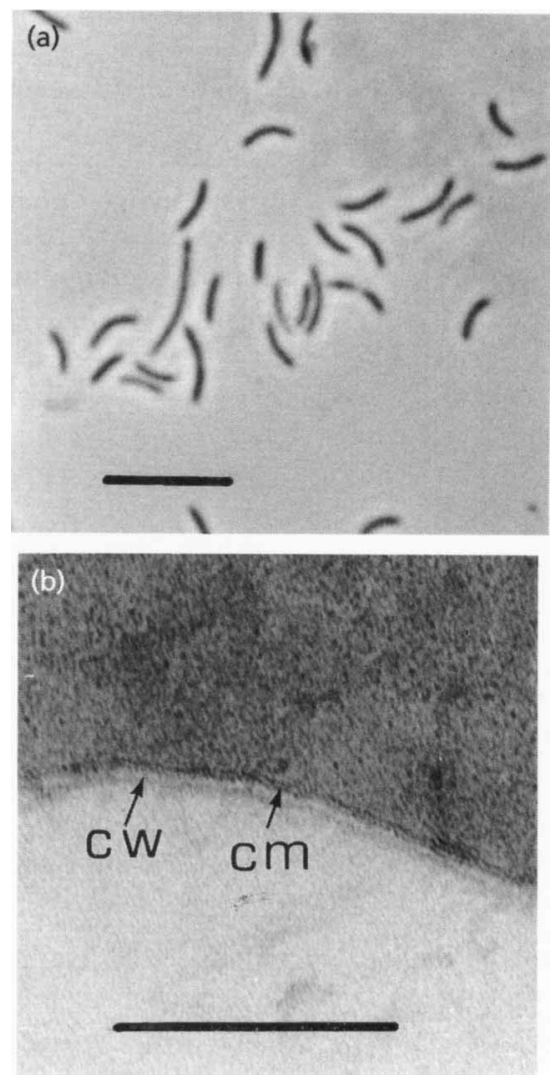

Fig. 1. (a) Phase photomicrograph of strain $S R 1^{\top}$ depicting curved cells. Bar, $10 \mu \mathrm{m}$. (b) Transmission electron micrograph of the cell wall ultrastructure of strain $\mathrm{SR}^{\top}{ }^{\top}$ showing the presence of cytoplasmic membranes $(\mathrm{cm})$ and a thick electrondense cell wall (cw). Bar, $0.2 \mu \mathrm{m}$.

\section{Substrate utilization}

Strain SR $1^{\mathrm{T}}$ used crotonate $(20 \mathrm{mM})$, methanol $(20 \mathrm{mM})$ and some aromatic compounds $(5 \mathrm{mM} ; 2,3-$ dimethoxybenzoate, 3,4-dimethoxybenzoate, TMB, TMC, TMPA, TMPP, syringate, sinapate, vanillate, ferulate, gallate, 2,4,6-trihydroxybenzoate, pyrogallol, phloroglucinol and quercetin) but was unable to utilize carbohydrates ( $20 \mathrm{mM}$; glucose, fructose, sucrose, xylose, sorbose, galactose, myo-inositol, lactose, ribose, mannitol and cellobiose), organic acids (20 mM; formate, fumarate, pyruvate, malonate and succinate), alcohols ( $20 \mathrm{mM}$; ethanol, propanol and butanol), $\mathrm{H}_{2}+\mathrm{CO}_{2}(80: 20 \%$, at $200 \mathrm{kPa})$ or a few aromatic compounds (5 mM; benzoate, 2-, 3-, 4-methoxybenzoates and 2,4-, 2,5-, 2,6- and 3,5dimethoxybenzoates). Yeast extract $(0 \cdot 2 \%)$ stimulated (but was not required for) growth.

\section{Fermentation end products}

Acetate and butyrate were produced from gallate, THB, pyrogallol, phloroglucinol, quercetin and crotonate, whereas acetate, butyrate and MTwere produced 
Table 1. Fermentation end products from aromatic compound degradation

DHB, dihydroxybenzoate; DHC, dihydroxycinnamate; ND, no aromatic structure detected as the ring was cleaved; U1, unidentified product.

\begin{tabular}{|c|c|c|c|c|c|c|}
\hline \multirow{2}{*}{$\begin{array}{l}\text { Aromatic compounds } \\
\text { tested }(5 \mathrm{mM})\end{array}$} & \multicolumn{3}{|c|}{ End products produced in presence of $\mathrm{H}_{2}$} & \multicolumn{3}{|c|}{ End products produced in absence of $\mathrm{H}_{2}$} \\
\hline & $\begin{array}{l}\text { Acetate } \\
(\mathbf{m M})\end{array}$ & $\begin{array}{l}\text { Butyrate } \\
(\mathbf{m M})\end{array}$ & $\begin{array}{l}\text { Aromatic structure } \\
\text { detected in end } \\
\text { products }\end{array}$ & $\begin{array}{l}\text { Acetate } \\
(\mathbf{m M})\end{array}$ & $\begin{array}{l}\text { Butyrate } \\
(\mathbf{m M} \mathbf{M})\end{array}$ & $\begin{array}{l}\text { Aromatic structure } \\
\text { detected in end } \\
\text { products }\end{array}$ \\
\hline 2,3-Dimethoxybenzoate* & $4 \cdot 2$ & $<1$ & Catechol and 2,3-DHB & 4 & $<1$ & Catechol and 2,3-DHB \\
\hline 3,4-Dimethoxybenzoate* & $4 \cdot 4$ & $<1$ & Catechol and 3,4-DHB & $4 \cdot 2$ & $<1$ & Catechol and 3,4-DHB \\
\hline $\mathrm{TMB}^{* \dagger}$ & $6 \cdot 5$ & $4 \cdot 5$ & ND & $8 \cdot 2$ & $2 \cdot 5$ & Pyrogallol \\
\hline $\mathrm{TMC}^{* \dagger}$ & $6 \cdot 4$ & $4 \cdot 6$ & ND & 8 & $2 \cdot 5$ & Pyrogallol \\
\hline $\mathrm{TMPA}^{*} \dagger$ & 6 & $3 \cdot 8$ & Pyrogallol & $7 \cdot 6$ & 2 & Pyrogallol \\
\hline TMPP*† & $6 \cdot 2$ & 4 & Pyrogallol & $7 \cdot 8$ & $2 \cdot 2$ & Pyrogallol \\
\hline Syringate* ${ }^{*}$ & 7 & 5 & ND & 10 & 3 & Pyrogallol \\
\hline Vanillate* & 5 & $<1$ & Catechol and 3,4-DHB & 5 & $<1$ & Catechol and 3,4-DHB \\
\hline Ferulate* & $4 \cdot 8$ & $<1$ & Catechol and 3,4-DHC & 4 & $<1$ & Catechol and 3,4-DHC \\
\hline Gallate ${ }^{\dagger}$ & $5 \cdot 6$ & $4 \cdot 3$ & $\mathrm{ND}$ & 7 & $<1$ & Gallate \\
\hline $\mathrm{THB} \dagger$ & 6 & 4 & ND & $6 \cdot 8$ & $<1$ & THB \\
\hline Pyrogallol $\dagger$ & 6 & $4 \cdot 2$ & ND & 8 & $<1$ & Pyrogallol \\
\hline Phloroglucinol $\dagger$ & $6 \cdot 2$ & $4 \cdot 4$ & ND & $8 \cdot 5$ & $<1$ & Phloglucinol \\
\hline Quercetint & 10 & 6 & UI & 11 & $<1$ & UI \\
\hline
\end{tabular}

* Compounds from which MT was produced.

$\dagger$ Compounds in which the aromatic rings were cleaved.

from 2,3-dimethoxybenzoate, 3,4-dimethoxybenzoate, TMC, TMB, TMPA, TMPP, syringate, sinapate, vanillate, ferulate and methanol (Table 1).

\section{Effect of the gas phase on aromatic-compound degradation by strain SR $1^{\top}$}

Concentrations of syringate as high as $12 \mathrm{mM}$ were completely transformed within $4 \mathrm{~d}$ incubation in the presence of $\mathrm{H}_{2}$ but after $7 \mathrm{~d}$ in the absence of $\mathrm{H}_{2} . \mathrm{H}_{2}$ was also observed to accelerate the growth of strain $\mathrm{SR} 1^{\mathrm{T}}$ on syringate and to shorten the growth lag time ( $4 \mathrm{~d}$ in the absence of $\mathrm{H}_{2}$ but $1 \mathrm{~d}$ in the presence of $\mathrm{H}_{2}$ ) (Fig. 2a). The ratio of acetate to butyrate produced was $10: 9$ when $\mathrm{H}_{2}$ was present and $16: 2$ when $\mathrm{H}_{2}$ was absent (Fig. 2b); the net carbon equivalent volatile fatty acids was also higher $(60 \mathrm{mM})$ in the presence of hydrogen than in its absence $(40 \mathrm{mM})$ (Fig. 2c).

\section{Electron acceptors}

Sulfate, thiosulfate, sulfite, nitrate, elemental sulfur and fumarate were not used as electron acceptors

\section{$\mathbf{G}+\mathbf{C}$ content}

The $\mathrm{G}+\mathrm{C}$ content of strain $\mathrm{SR} 1^{\mathrm{T}}$ was $38 \mathrm{~mol} \%$ as determined by the HPLC method.

\section{$16 \mathrm{~S}$ rRNA sequence analysis}

Using 12 primers, we determined an almost complete sequence consisting of 1511 bases of the 16S rRNA gene of strain $\mathrm{SRI}^{\mathrm{T}}$ (corresponding to E. coli positions 13-1532). Phylogenetic analysis revealed that strain $S R 1^{\mathrm{T}}$ was a member of cluster XIVa of the low $\mathrm{G}+\mathrm{C}$ Gram-positive branch as defined by Collins et al. (1994). The closest relatives were Eubacterium fissicatena or Clostridium aminovalericum (with a sequence similarity of $90 \%$ ) depending on the selection of representative members of the cluster in tree construction. Fig. 3 represents a dendrogram generated by the neighbour-joining method of the Jukes-Cantor evolutionary distance matrix (Jukes \& Cantor, 1969) in which strain $\mathrm{SR} 1^{\mathrm{T}}$ is located next to Clostridium aminovalericum.

\section{DISCUSSION}

\section{Ecology}

Strain SR $1^{\mathrm{T}}$ was isolated from an anaerobic digester fed with olive mill wastewater. It utilized a range of carbon and energy sources composed exclusively of aromatic compounds, methanol and crotonate. The presence of such a strain in the olive mill wastewater treatment digester is not surprising as the wastewater contains a wide range of aromatic compounds that are released from the olive cell walls during the oilextraction process (Capasso et al., 1995). Because the 

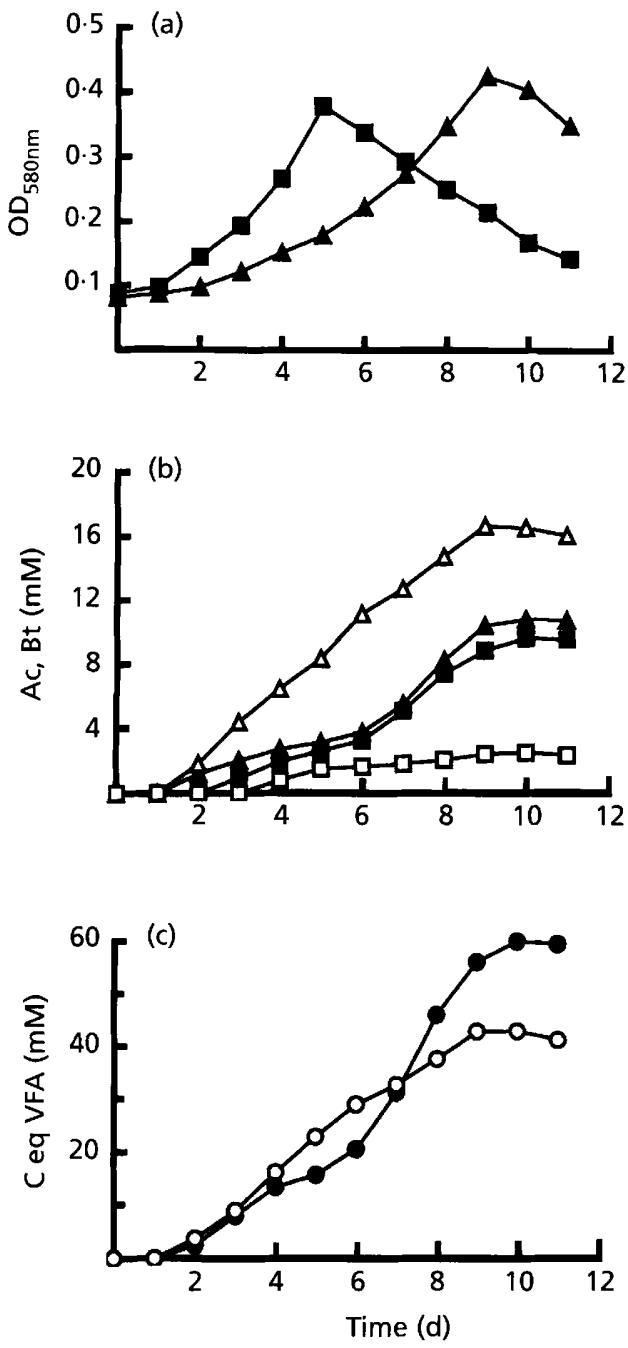

Fig. 2. (a) Growth of strain $S R 1^{\top}$ in a basal medium containing $12 \mathrm{mM}$ syringate $(\boldsymbol{A})$ and $12 \mathrm{mM}$ syringate plus hydrogen $(\boldsymbol{D})$. (b) End products from $12 \mathrm{mM}$ syringate degradation by strain $S R 1^{\top}$ in the presence of hydrogen [acetate $(\boldsymbol{A})$ and butyrate $(\boldsymbol{D})$ ] or in the absence of hydrogen [acetate $(\triangle)$ and butyrate ( $\square)$ ]. Ac, acetate; Bt, butyrate. (c) The total carbon transformed to acetate and butyrate by strain SR $1^{\top}$ during degradation of $12 \mathrm{mM}$ syringate (represented as carbon equivalent volatile fatty acid, which is the sum of the carbon transformed to acetate and the carbon transformed to butyrate) in the presence of hydrogen (O) and in the absence of hydrogen, (O). $C$ eq VFA, carbon equivalent volatile fatty acid.

aromatic ring of methoxylated aromatic compounds cannot be cleaved, demethoxylation is the initial key reaction for subsequent degradation of these compounds. Strain SR $1^{\mathrm{T}}$ and several other strains isolated from the same digester have been observed to demethoxylate aromatic compounds efficiently (unpublished results).

\section{Physiology}

The cleavage of aromatic compounds such as methoxybenzoates (syringate, TMB) by strain $\mathrm{SR} 1^{\mathrm{T}}$ is a trait shared by $H$. foetida and Sporobacter termitidis.
However, there are numerous physiological differences that distinguish the former from the two latter species. Strain SR $1^{\mathrm{T}}$ and $H$. foetida have the ability to degrade a wide range of aromatic substrates but Sporobacter termitidis has a limited capacity; for example, it is unable to degrade trihydroxybenzenes and trihydroxybenzoates. Strain $\mathrm{SR} 1^{\mathrm{T}}$ produces acetate and butyrate from aromatic compound degradation and produces MT from sulfide and methoxyl groups of aromatic compounds. However, H. foetida and Sporobacter termitidis produce acetate as the only end product from aromatic compound degradation and MT and produce DMS from sulfide and methoxyl groups of aromatic compounds. DMS formation has been shown to proceed via MT (Bak et al., 1992) but in the case of strain SR $1^{\mathrm{T}} \mathrm{DMS}$ has never been detected, indicating that this strain is unable to transfer the methyl group to MT.

Both strain SR $1^{\mathrm{T}}$ and Eubacterium oxidoreducens have the ability to degrade trihydroxybenzenes (gallate, pyrogallol and phloroglucinol) and quercetin. However, Eubacterium oxidoreducens has an obligate requirement for hydrogen or formate as an external electron donor for this purpose. Strain SR $1^{\mathrm{T}}$ is able to degrade both trihydroxybenzenes and quercetin in the absence of hydrogen. In the presence of hydrogen it is able to degrade higher concentrations of trihydroxybenzenes and quercetin. The addition of formate as an electron donor has no effect on their degradation. A final difference is that Eubacterium oxidoreducens is unable to utilize methoxylated aromatic compounds and cannot produce MT or DMS, unlike strain SR $1^{\mathrm{T}}$.

\section{Phylogeny and taxonomy}

Phylogenetically, strain $S R 1^{\mathrm{T}}$ is related to either Eubacterium fissicatena (Taylor, 1972) or Clostridium aminovalericum (Hardman \& Stadtman, 1960) depending on which representative sequences are selected for use in tree construction. Therefore, the clustering of strain SR $1^{\mathrm{T}}$ with Clostridium aminovalericum depicted in Fig. 3 should be regarded as tentative until its position can be predicted with a greater degree of confidence. This would be likely to occur when other related members have been sequenced and added to this cluster.

The physiological and phenotypic data clearly show that strain $\mathrm{SR} 1^{\mathrm{T}}$ is different from both Eubacterium fissicatena and Clostridium aminovalericum. Strain $\mathrm{SR}^{\mathrm{T}}$ is a slightly curved, motile and spore-forming bacterium that utilizes aromatic compounds but not carbohydrates whereas Eubacterium fissicatena is a non-sporulating, rod-shaped bacterium that lacks motility and utilizes carbohydrates but not aromatic compounds. On the other hand, Clostridium aminovalericum is a motile spore-former like strain $\mathrm{SR} 1^{\mathrm{T}}$ but is rod-shaped, ferments carbohydrates and is not reported to utilize aromatic compounds. These and other major differences between the three strains are shown in Table 2. 


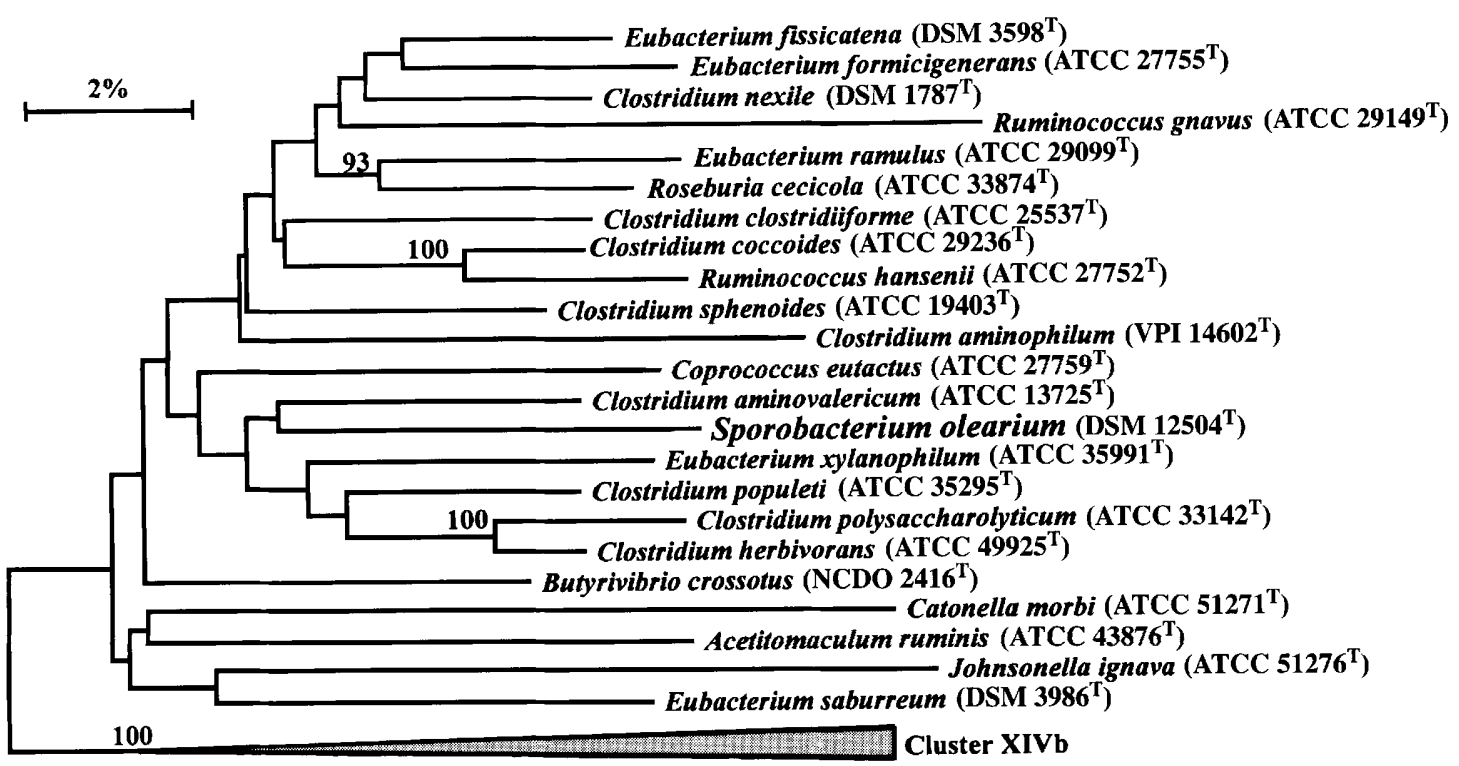

Fig. 3. Sporobacterium olearium (strain $\mathrm{SR} 1^{\top}=\mathrm{DSM} 12505^{\top}$ ) is a member of cluster XIVa of the Clostridiales group and is equidistant from Clostridium aminovalericum and Eubacterium fissicatena, its precise relationship to any one of them depending on the selection of strains of cluster XIVa. In this case the unrooted dendrogram depicted in the figure shows the nearest phylogenetic relative of Sporobacterium olearium to be Clostridium aminovalericum when members of the listed set of representatives of cluster XIVa are used in the analysis. The sequences represented in cluster XIVb (indicated by the shaded triangular region) were used as outgroups and include Clostridium lentocellum and Clostridium propionicum. The clusters are defined as suggested by Collins et al. (1994). All of the sequences used in the analysis were obtained from the Ribosomal Database Project, version 7.0 (Maidak et al., 1997). Bootstrap values, expressed as a percentage of 100 replications, are shown at the branching points. Only values above $90 \%$ were considered significant and therefore reported. Bar, 2 nucleotide substitutions per 100 nucleotides.

Table 2. Differentiating characteristics for strain $\mathrm{SR} 1^{\top}$, Eubacterium fissicatena and Clostridium aminovalericum

The characteristics of strain SR $1^{\mathrm{T}}$ were determined in this study. Culturing was performed in basal medium ( $\mathrm{pH} 7$ ) supplemented with substrates; the results were recorded after 2 weeks incubation at $37^{\circ} \mathrm{C}$. Data for Eubacterium fissicatena and Clostridium aminovalericum were taken from Taylor (1972) and Hardman \& Stadtman (1960), respectively. +, Positive reaction or present; -, negative reaction or absent; NR, not reported.

\begin{tabular}{|lccc|}
\hline Characteristic & Strain SR1 & E. fissicatena & C. aminovalericum \\
\hline Cell shape & Curved rods & Straight rods & Straight rods \\
Cell size $(\mu \mathrm{m})$ & $0 \cdot 4-0 \cdot 8 \times 5-10$ & $0 \cdot 3-0 \cdot 5 \times 0 \cdot 5-1$ & $0 \cdot 3-0 \cdot 5 \times 1 \cdot 5-5 \cdot 2$ \\
Motility & + & - & + \\
Sporulation & + & - & + \\
pH optimum & $7 \cdot 2$ & $\mathrm{NR}$ & $\mathrm{NR}$ \\
Temperature optimum $\left({ }^{\circ} \mathrm{C}\right)$ & $37-40$ & 37 & 37 \\
Temperature range $\left({ }^{\circ} \mathrm{C}\right)$ & $20-45$ & $13-37$ & $25-45$ \\
G+C content $(\mathrm{mol} \%)$ & 38 & 45 & 33 \\
Utilization of: & & & + \\
Glucose & - & + & - \\
Aromatics* & + & - & + \\
Proteinsं & - & $\mathrm{NR}$ & + \\
Aminovalerate & - & + & $\mathrm{NR}$ \\
Yeast extract $(0 \cdot 2 \%)$ & - & & \\
\hline
\end{tabular}

*Utilized at $5 \mathrm{mM}$ : TMB, TMC, TMPA, TMPP, syringate, vanillate, ferulate, 3,4-dimethoxybenzoate, 2,3-dimethoxybenzoate, gallate, THB, pyrogallol, phloroglucinol and quercetin.

$\dagger$ Peptone, meat extract. 
Strain $\mathrm{SR} 1^{\mathrm{T}}$ is physiologically unique and is the first aromatic compound-degrading bacterium that is also capable of utilizing methanol and producing acetate, butyrate and MT as end products of degradation. This, together with the phylogenetic and physiological evidence presented above, leads us to propose the designation of strain SR $1^{\mathrm{T}}$ as Sporobacterium olearium gen. nov., sp. nov.

\section{Description of Sporobacterium gen. nov.}

Sporobacterium (Spo.ro.bac.ter'ium. M.L. n. spora spore; Gr. neut. n. baktron rod; M.L. neut. n. Sporobacterium spore-forming rod).

A spore-forming slightly curved rod that stains Grampositive. It is motile, strictly anaerobic and ferments aromatic compounds, methanol and crotonate to produce MT from methyl groups and sulfide. The type species is Sporobacterium olearium.

\section{Description of Sporobacterium olearium sp. nov.}

Sporobacterium olearium (o.le.a'ri.um. L. adj. olearius $-a-u m$ of oil, related to olive oil, referring to the isolation of strain $\mathrm{SR} 1^{\mathrm{T}}$ from an olive mill wastewater treatment digester).

A slightly curved rod with a terminal spore. Stains Gram-positive. Motile, with peritrichous flagella. Strictly anaerobic chemo-organotrophic. Grows on crotonate, methanol, TMB, TMC, syringate, TMPA, TMPP, ferulate, sinapate, vanillate, 3,4-dimethoxybenzoate, 2,3-dimethoxybenzoate, gallate, THB, pyrogallol, phloroglycinol and quercetin. No growth with benzoate, 2-, 3-, 4-methoxybenzoates, 2,4-, 2,5-, 2,6-, 3,5-dimethoxybenzoates, glucose, fructose, sucrose, xylose, sorbose, galactose, myo-inositol, lactose, ribose, mannitol, cellobiose, formate, fumarate, pyruvate, malonate, succinate, ethanol, propanol, butanol or $\mathrm{H}_{2}+\mathrm{CO}_{2}$. Yeast extract stimulates (but is not required for) growth. TMB, TMC, TMPA, TMPP, syringate, sinapate, 2,3-dimethoxybenzoate, 3,4-dimethoxybenzoate, vanillate, ferulate and methanol are fermented to acetate, butyrate and MT. Gallate, THB, pyrogallol, phloroglucinol and crotonate are fermented to acetate and butyrate. $\mathrm{H}_{2}$ is not required for growth but is required for complete degradation of gallate, THB, pyrogallol and phloroglucinol. Sulfate, thiosulfate, sulfite, nitrate, elemental sulfur and fumarate are not reduced. The optimal growth temperature is between 37 and $40^{\circ} \mathrm{C}$ (the temperature growth range being $25-45^{\circ} \mathrm{C}$ ). The optimum $\mathrm{pH}$ for growth is $7 \cdot 2$ (the $\mathrm{pH}$ growth range being between 6.5 and 8.5 ). Grows with $\mathrm{NaCl}$ concentrations between 0 and $30 \mathrm{~g}$ $\mathrm{l}^{-1}$ but not with $35 \mathrm{~g}^{-1}$. The DNA G $+\mathrm{C}$ content is 38 mol\%. The habitat is an anaerobic methanogenic digester fed with olive mill wastewater (Tunisia). The type strain is $\mathrm{SR} 1^{\mathrm{T}}\left(=\mathrm{DSM} 12504^{\mathrm{T}}\right)$.

\section{ACKNOWLEDGEMENTS}

The financial assistance, in part to B.K.C.P., from the Australian Research Council is gratefully acknowledged.

\section{REFERENCES}

Altschul, S. F., Madden, T. L., Schäffer, A. A., Zhang, J., Zhang, Z., Miller, W. \& Lipman, D. J. (1997). Gapped BLAST and PSI-BLAST: a new generation of protein database search programs. Nucleic Acids Res 25, 3389-3402.

Andrews, K. T. \& Patel, B. K. C. (1996). Fervidobacterium gondwanense sp. nov., a new thermophilic anaerobic bacterium isolated from nonvolcanically heated geothermal waters of the Great Artesian Basin of Australia. Int $J$ Syst Bacteriol 46, 265-269.

Bak, F., Finster, K. \& Rothfuß, F. (1992). Formation of dimethylsulfide and methanethiol from methoxylated aromatic compounds and inorganic sulfide by newly isolated anaerobic bacteria. Arch Microbiol 157, 529-534.

Benson, D., Lipman, D. J. \& Ostell, J. (1993). GenBank. Nucleic Acids Res 21, 2963-2965.

Brauman, A., Muller, J. A., Garcia, J.-L., Brune, A. \& Schink, B. (1998). Fermentative degradation of 3-hydroxybenzoate in pure culture by a novel strictly anaerobic bacterium, Sporotomaculum hydroxybenzoicum gen. nov., sp. nov. Int $J$ Syst Bacteriol 48, 215-221.

Capasso, R., Evidente, A., Schivo, L., Orru, G., Marcialis, M. A. \& Cristinzio, G. (1995). Antibacterial polyphenols from olive oil mill waste waters. $J$ Appl Bacteriol 79, 393-398.

Collins, M. D., Lawson, P. A., Willems, A., Cordoba, J. J., Fernandez-Garayzabal, J., Garcia, P., Cai, J., Hippe, H. \& Farrow, J. A. E. (1994). The phylogeny of the genus Clostridium: proposal of five new genera and eleven new species combinations. Int $J$ Syst Bacteriol 44, 812-826.

Fardeau, M.-L., Ollivier, B., Patel, B. K. C., Magot, M., Thomas, P., Rimbault, A., Rocchiccioli, F. \& Garcia, J.-L. (1997). Thermotoga hypogea sp. nov., a xylanolytic, thermophilic bacterium from an oil-producing well. Int J Syst Bacteriol 47, 1013-1019.

Felsenstein, J. (1993). PHYLIP (Phylogeny Inference Package) version $3<\mathrm{PT}>51 \mathrm{c}$. Department of Genetics, University of Washington, Seattle, USA.

Grech-Mora, I., Fardeau, M.-L., Patel, B. K. C., Ollivier, B., Rimbault, A., Prensier, G., Garcia, J.-L. \& Garnier-Sillam, E. (1996). Isolation and characterization of Sporobacter termitidis gen. nov., sp. nov., from the digestive tract of the wood-feeding termite Nasutitremes lujae. Int J Syst Bacteriol 46, 512-518.

Hardman, J. K. \& Stadtman, T. C. (1960). Metabolism of $\omega$ amino acid. II. fermentation of $\Delta$-aminovaleric acid by $\mathrm{Clo}-$ stridium aminovalericum. $J$ Bacteriol 79, 549-552.

Hungate, R. E. (1969). A roll-tube method for the cultivation of strict anaerobes. Methods Microbiol 136, 194-198.

Jukes, T. H. \& Cantor, C. R. (1969). Evolution of protein molecules. In Mammalian Protein Metabolism, pp. 211-232. Edited by H. N. Munro. New York: Academic Press.

Krumholz, L. R. \& Bryant, M. P. (1986). Eubacterium oxidoreducens sp. nov. requiring $\mathrm{H}_{2}$ or formate to degrade gallate, pyrogallol, phloroglucinol and quercetin. Arch Microbiol 144, 8-14.

Liesack, W., Bak, F., Kreft, J. U. \& Stackebrandt, E. (1994). Holophaga foetida gen. nov., sp. nov., a new homoacetogenic bacterium degrading methoxylated aromatic compounds. Arch Microbiol 162, 85-90. 
Macy, J. M., Snellen, J. E. \& Hungate, R. E. (1972). Use of syringe methods for anerobiosis. Am J Clin Nutr 25, 1318-1323.

Maidak, B. L., Olsen, G. J., Larsen, N., Overbeek, R., McCaughey, M. J. \& Woese, C. R. (1997). The RDP (Ribosomal Database Project). Nucleic Acids Res 25, 109-111.

Mechichi, T., Labat, M., Patel, B. K. C., Woo, T. H. S., Thomas, P. \& Garcia, J.-L. (1999). Clostridium methoxybenzovorans sp. nov., a new aromatic $o$-demethylating homoacetogen from an olive mill wastewater treatment digester. Int $J$ Syst Bacteriol 49, 1201-1209.

Mesbah, M., Premachandran, U. \& Whitman, W. B. (1989). Precise measurement of the $\mathrm{G}+\mathrm{C}$ content of deoxyribonucleic acid by high-performance liquid chromatography. Int $J$ Syst Bacteriol 39, 159-167.

Miller, T. L. \& Wolin, M. J. (1974). A serum bottle modification of the Hungate technique for cultivating obligate anaerobes. Appl Microbiol 27, 985-987.

Patel, T. R., Jure, K. G. \& Jones, G. A. (1981). Catabolism of phloroglucinol by the rumen anaerobe Coprococcus. Appl Environ Microbiol 42, 1010-1017.

Redburn, A. C. \& Patel, B. K. C. (1993). Phylogenetic analysis of Desulfotomaculum thermobenzoicum using polymerase chain reaction-amplified 16S rRNA-specific DNA. FEMS Microbiol Lett 113, 81-86.
Schink, B. \& Pfennig, N. (1982). Fermentation of trihydroxybenzenes by Pelobacter acidigallici gen. nov., sp. nov., a new strictly anaerobic, non-spore-forming bacterium. Arch Microbiol 133, 195-201.

Schnell, S., Brune, A. \& Schink, B. (1991). Degradation of hydroxyquinone by the strictly anaerobic fermenting bacterium Pelobacter massiliensis sp. nov. Arch Microbiol 155, 512-516.

Szewzyk, U. \& Schink, B. (1989). Degradation of hydroquinone, gentisate, and benzoate by a fermenting bacterium in pure or defined mixed culture. Arch Microbiol 151, 541-545.

Taylor, M. M. (1972). Eubacterium fissicatena sp. nov., isolated from the alimentary tract of the goat. J Gen Microbiol 71, $457-463$.

Van de Peer, Y. \& De Wachter, R. (1993). TREECON: a software package for the construction and drawing of evolutionary trees. CABIOS 9, 177-182.

Widdel, F. \& Pfennig, N. (1981). Studies on dissimilatory sulfatereducing bacteria that decompose fatty acids. Isolation of new sulfate reducing bacteria enriched with acetate from saline environments. Description of Desulfobacter postgatei gen. nov., sp. nov. Arch Microbiol 129, 395-400.

Winker, S. \& Woese, C. R. (1991). A definition of the domain Archaea, Bacteria and Eucarya in terms of small subunit rRNA characteristics. Syst Appl Microbiol 13, 161-165. 